of new overall mechanisms for apportioning nationally the cost of industrial training and large-scale research projects. This is particularly true if co-operation is to be extended with the medium- and smaller-sized firms, the finances of which will not pormit an altruistic attitude towards their profit and loss accounts. The fourth prerequisite is the recruitment of staff, both of the quality and in the quantity required. In order to reach the target of 40,000 students, we may estimate that an additional 3,500 teachers are required. A proportion of these need to be men of very great ability either drawn from in. dustry or sharing their activities betweon industry and College. Some of these will inevitably be in short supply in the initial period until their work in industry can be supplemented by the new supply of people coming from the Colleges. Novertheless, the financial factors, particularly salaries and facilities for research, must be faced realistically. The point is that if the top staff of Colleges of Advanced. Technology are to be responsible for training future leaders of industry, they must themselves be men of the highest calibre. The fifth condition for sucess has already been dealt with to some extent when we were considering the problems of entrants and selection. It is that of co-operation with the schools. During the past fow years this has doveloped to an unprecedented extent and a good many of the barriers of misunderstanding have begun to be brokon down. In one College, for example, the staff make perhaps something like one hundred visits per year to the schools in the region, and several thousands of school boys and girls come in contact with the College. Increasingly, the staff at the schools are visiting the Colleges, taking part in symposia and conferences and special courses, and are beginning to appreciate something of the requirements and objectives. Nevertheless, it remains, from the long term point of view, highly desirable, if an adequate stream of our talented young people are to find their places in the Colleges of Advanced Technology as well as in university departments of applied science and technology, that now methods of teaching science should be experimented with and that a stream of industrially experienced teachers should find their way into the schools.

After a long induction period, higher technological education in Britain, through the medium of the Colleges of Advanced Technology, has taken the initiative in a new experiment, the construction of a fully viable and self-supporting spectrum of study and research, deliberately harnessed to supplying industrial and social noeds. Tho impetus of their dosignation has carried them forward with a rate of expansion creating many problems demanding complete re-appraisal of our whole philosophy of scientific and technological education. Much of their work carries the inevitable marks of haste and improvisation. It is now essential that the administrative and organizational measures necessary for them to develop autonomously and with full momentum should be put into operation without delay.

1 Edwards, E. G., Technology, 6, No. 2, 39 (1962).

${ }^{2}$ Industrial Research in Manufacturing Industry, 24 (Federation of British Industries, 1961).

${ }^{3}$ Gerstl, J. E., New Society, No. 36, 19 (June 6, 1963).

Rep. Central Adv. Counc. for Education (England), 2, 116 (H.M.S.O., 1960) Technology and the Sixth Form Boy (Oxford University Department of Education, 1963). See also, Nature, 199, 958 (1963).

- Irving, H., The Three Cultures (Leeds Univ. Press, 1903). [See also Nature, 199,$627 ; 1963$.]

\title{
OBITUARIES
}

\section{Prof. J. J. Sudborough}

Dr. John Joseph SUDBorough died at his home in Torquay on July 25 at the age of ninety-three.

Born in Birmingham in 1869, he was educated at the Camp Hill Grammar School and in 1886 entered Mason's College with School and Entrance scholarships. He studied mainly under Profs. Tilden and Lapworth and graduated B.Sc.(London) in 1889 with double first-class honours in chemistry and geology.

Two years research work under Prof. Tilden followed, the subject being the additive reactions of nitrosyl chloride with olefines. In 1891 he obtained one of the first scholarships offered by the Commissioners of the 1851 Exhibition and proceeded to the University of Heidelberg, where he worked under Prof. Victor Meyer on stilbene derivatives. He graduated Ph.D. in 1893 and continued for a further year as private assistant to Victor Meyer, working on the subject of 'steric hindrance' as shown by diortho-substituted benzoic acids.

Returning to Britain, he worked for a period at Owens College, Manchester, and obtained a D.Sc.(London) degree. He was then appointed lecturer in organic chemistry at University College, Nottingham, under Profs. Clowes and Kipping, and there continued research, with student assistanco, on 'steric hindrance' and on the additive compounds of trinitro-derivatives of bonzene.

In 1901 he succeeded Dr. Lloyd Snape as professor of chomistry at University College of Wales, Aberystwyth. It was a time of great activity in Wales, for the University had been established in 1896 and the new intermediate schools were sending their matriculated pupils to the Collegos. Sudborough quickly realized his opportunity, organized an honours degree course and a research school and secured increased accommodation for his rapidly expanding department. A fow years later, tho generosity of Mr. David Davies (afterwards Lord Davies) and his Llandinam family enabled the College, in 1907, to orect the Edward Davies Momorial Laboratories, the equipment of which the professor supervised with meticulous care and of which he became the first director. During his decade of service at Aberystwyth, Sudborough taught and trained in research many men who later occupied important positions in the scientific world. He also took a leading part in College administration, served as dean of the Faculty of Science and as an officer in the Officers' Training Corps Contingent.

In 1911, after the death of his wife, ho accepted the appointment as professor of organic chemistry at the Indian Institute of Science, Bangalore. Here, in association with the director, Dr. M. W. Travers, he inaugurated the work of the Chemistry Departments and developed a sound and thorough system of training in organic chemistry. In 1914 Dr. Travers retired, and Sudborough became head of the Departments of General and Organic Chemistry with Dr. H. E. Watson as assistant profossor. Their output of papers, many of technical importance, was afterwards considerablo.

After retirement in 1926 he lived at Ermington, South Devon, where he took much interest in local affairs and served on the Plympton Rural District Council. Later, moving to Torquay, he becamo honorary secretary for many years of the Torquay Natural History Society. He became a life governor of the University Colloge of Wales and served for many years on its Council.

He was twice married, first to Miss $J$. Hunter, of Belfast, and secondly to Miss Elsie Boan, daughter of Mr. A. Bean, sometime postmaster-general of tho Punjab, who survives him. He leaves no children.

T. CAMpbeni James

\section{Dr. B. Lambert, O.B.E.}

Dr. Bertram Lambert died on July 1, aged eightyone. For half a century, as undergraduate, demonstrator, 
and finally as administrative head, he was associated with the laboratory first called the Chemistry Department, University Museum, Oxford, then the Old Chemistry Department, and later the Inorganic Chemistry Laboratory. $\mathrm{H} \theta$ went up to Oxford from Giggleswick School as exhibitioner at Merton College, and obtained a first class in chemistry in the Final Honours School of 1903. The head of the Department, Prof. Odling, appointed him to the small body of demonstrators whose duties were to lecture and to teach, but with no encouragement or example towards research. Lambert, however, as an undergraduate had received a taste of the new physical chemical methods of measurement which had just been introduced from Ostwald's Laboratory in Germany into the undergraduate course at the Daubeny Laboratory belonging to Magdalen College. Single-handed he began to prepare himself for original work, which in those days was concentrated on the development of techniques for achieving the highest accuracy of physical measurements on chemical substances. Everything needed to be done the hard way. By intensive and methodical late-night practice, Lambert made himself equal to a professional in glass-blowing, and highly skilled in the laboratory arts of apparatus construction. Having no technical assistance, he made his own vacuum pumps, traps, manometers, internal heating devices, and often his own taps (all, in early days, of soda glass). This manipulative skill culminated in the construction of a quartz microbalance for the measurement of gaseous densities (Phil. Trans. Roy. Soc., 1950), whereby the atomic weights of carbon and nitrogen were determined with an accuracy of 5 parts in $10^{5}$.

His first published work related to the rusting of iron, and involved lengthy experiments on the preparation of highly purified water, oxygen and iron, from which he concluded that the rusting process was essentially of an electrolytic nature, a view which was only to find general acceptance many years later. After the First World War, he took up the study of adsorption of gases with a long series of carefully planned experiments on the palladiumhydrogen system and on the equilibria of vapours and gases with ferric-oxide and silica gels. This work brought out the difficulties of the subject associated with hysteresis effects. A paper published in 1939 showed how, by the most careful attention to detail, chemical methods of gas analysis could be brought to an accuracy of 0.02 per cent on a total volume of only 10 c.c. During all this work he was continually perfecting matters of technique and methods of achieving the highest purity of the gases used; particular reference may be made to his preparation of pure nitrogen. The elaborate care he constantly took meant that his output of publications was not large; his involvement in the planning and technique of measurement often seemed to exceed his interest in the significance of the results. His sound instruction in method, however, was invaluable to students who worked under his supervision.

Dr. Lambert is perhaps best known for his initiative in the First World War towards the production of respirators. Immediately after the first gas attack, the Army set up a defence organization under Col. Horrocks, assisted by Col. Harrison and Major Sadd, and early trials were made of respirators of impregnated cloth of Balaclava helmet shape. As early as June 1915 Lambert, while on leave from the Royal Engineers, himself constructed a box-type respirator with soda-lime-permanganate granules as absorbing agent. He took this to the War Office, and his principle was quickly recognized as superior to all other proposals. In the following year box-respirators with Lambert's granules, together with charcoal, were issued. to the troops, and continued in use throughout the War. This contribution was recognized later by a substantial monetary award from a War Inventions Board of scientists and by an O.B.E. from the Government.

As soon as the First World War was over, Lambert returned to Oxford and was elected Fellow of Merton College. Additional responsibilities came easily to him. Besides carrying a full load of tutorial teaching, laboratory demonstration and research, he was called on to act as mediator and peace-maker in disagreements during the early part of Prof. Soddy's tenure of the chair. When Soddy retired he effectively administered the Inorganic Chemical Laboratory until his own retirement in 1947. $\mathrm{He}$ was active in all affairs and committees relating to chemistry at Oxford, and served helpfully as a member of the University Chest during the Second World War.

Lambert possessed the virtues of a true Yorkshireman: cheerfulness, sociability, self-reliance, moderation, appreciation of honest, hard work, and wise judgment of men and things. He enjoyed playing cricket when young, and bowls and golf in later years. His marriage to Sylvia Dewe in 1908 was a happy one; she survives him. His daughter, Peggy, is married to Group Captain Peter Broad, and his son, James Dewe Lambert, is Fellow of Trinity College and University lecturer in chemistry at Oxford.

\section{NEWS and VIEWS}

\section{The University of Strathclyde}

IT has recently been announced that the Royal College of Science and Technology, Glasgow, has received its charter as the fifth university in Scotland. This important development in university education in Scotland was described by Dr. S. C. Curran, principal of the College, in Nature of August 31, p. 843. It has now been announced that the new name of the Royal College is to be University of Strathclyde. Lord Todd, professor of organic chemistry in the University of Cambridge, has been elected the first chancellor. Dr. Curran is to be the first principal and vicechancellor. The University of Strathclyde will naturally devote itself to the advancement of learning mainly through the fundamental and applied sciences. Unlike the other four universities in Scotland it will not have a Rector.

\section{U.S. Air Force Office of Scientific Research :}

$$
\text { Dr. W. J. Price }
$$

Dr. Wirliam J. Price, former chief scientist of the Aerospace Research Laboratories, Wright-Patterson Air Force Base, Ohio, has been appointed executive director of the U.S. Air Force Office of Scientific Research, Washington. The Air Force Office of Scientific Research is responsible for the administration of grant and contract awards to industry, universities and other institutions whose proposals for research projects have been selected. by the Air Force for support. Dr. Price was chief of the Modern Physics Research Branch at the Aerospace Research Laboratories prior to becoming chief scientist there in 1959. Since receiving his Doctorate in Physics from Rensselaer Polytechnic Institute in 1948, he has worked almost continuously for the Government. During 1949-54 he was associate professor of physics at the Air Force Institute of Technology (AFIT). In February 1954 he was appointed head of the Department of Physics there. He held this post until 1957, when he went to the Aerospace Research Laboratories as ehief of the Modern Physics Research Branch.

\section{The Finance of Education}

THE report of a conference on the finance of education, organized by the 1963 Campaign for Education, and 